\title{
Artículos
}

\section{Inmigrantes haitianos y dominico-haitianos en República Dominicana. Cambios y posibles implicaciones de los perfiles}

\author{
Haitian and Dominican-Haitian immigrants \\ in the Dominican Republic. Changes and possible \\ implications of profiles
}

\author{
Schwarz Coulange Méroné*
}

\begin{abstract}
Resumen
En este artículo analizamos las principales características de los inmigrantes haitianos y los dominicanos de ascendencia haitiana (dominico-haitianos) en República Dominicana. Examinamos algunos cambios y continuidades en el perfil de inmigrantes haitianos en este país y resaltamos las diferencias sociodemográficas entre ambos grupos. Los datos sugieren que una parte significativa de la población de origen haitiano es susceptible de radicar por tiempos relativamente largos en República Dominicana, lo cual conllevaría implicaciones para el futuro de dicha migración, particularmente la referida a la naturaleza de los lazos entre la diáspora haitiana en República Dominicana y la población no migrante de Haití, y, más ampliamente, para las relaciones entre los dos países involucrados.
\end{abstract}

Palabras clave: migración Haití-República Dominicana; inmigrantes haitianos; dominico-haitianos; perfiles.

\begin{abstract}
In this article, we analyze the main characteristics of Haitian immigrants and Dominicans of Haitian descent (Dominican-Haitians) in the Dominican Republic. We examine some of the changes and continuities in the profile of Haitian immigrants in this country and highlight the sociodemographic differences between the two groups. The data suggest that a significant part of the population of Haitian origin is likely

* El Colegio de México, A.C., Centro de Estudios Demográficos, Urbanos y Ambientales. Dirección postal: Carretera Picacho Ajusco 20, Ampliación Fuentes del Pedregal, 14110, Tlalpan, Ciudad de México, México. Correo electrónico: smerone@colmex.mx
\end{abstract}


to reside in the Dominican Republic for relatively long periods, which would entail implications for the future of this migration, particularly the nature of the ties between the Haitian diaspora in the Dominican Republic and the non-migrant population of Haiti, and, more broadly, for relations between the two countries involved.

Keywords: Haiti-Dominican Republic migration; Haitian immigrants; Dominican-Haitians; profiles.

\section{Introducción}

Desde hace aproximadamente cien años ha venido consolidándose un flujo migratorio originado en Haití que se dirige a República Dominicana. Esta migración, que en principio era parte de una dinámica económica regional, se complejizó a través de las décadas debido a factores propios de los dos países involucrados y a procesos globales. En específico, a partir de la década de los ochenta del siglo pasado, en respuesta a diversos sucesos ocurridos en los dos países, los perfiles de los inmigrantes haitianos en República Dominicana comenzaron a variar abarcando a un abanico cada vez más amplio de categorías de personas (Silié, Segura y Dore, 2002). Además, las personas nacidas en República Dominicana de padres haitianos se han afirmado como un grupo distinto en cuanto a sus rasgos sociodemográficos, la intensidad de las interacciones con el resto de la sociedad dominicana, y la especificidad de las problemáticas que plantean, especialmente las relacionadas con la identidad sociocultural y la nacionalidad (Perdomo Cordero, 2016; Silié, Segura y Dore, 2002).

Basándose en la diversificación de los perfiles de los inmigrantes y la configuración sociodemográfica de sus hijos nacidos en aquel país, algunos autores empezaron a hablar de una nueva inmigración haitiana en República Dominicana (Silié, Segura y Dore, 2002). En años recientes, diversos estudios han permitido conocer más sobre los integrantes de esa nueva migración, especialmente en cuestiones relacionadas con las condiciones de trabajo, los procesos de integración, la identidad, la documentación, la nacionalidad, los derechos humanos, entre otros temas (Riveros, 2014; Duarte et al., 2011; Flacso/OIM, 2004; Contreras, 2004; Wooding y Moseley-Williams, 2004; Silié, Segura y Dore, 2002; Tejada, 2001; Lozano, 2005, 1998). Sin embargo, pocos estudios se han dedicado a analizar las características de los haitianos más allá de su relación con los mercados laborales nacionales haitiano y dominicano. Por ejemplo, aparte de los cambios económicos y laborales en los dos países, ¿qué otro factor explica la creciente feminización del flujo migratorio?, ¿cómo podemos explicar las diferencias sociode- 
mográficas entre los inmigrantes y sus hijos nacidos en Dominicana, es decir, los dominico-haitianos?, ¿qué nos dice la configuración de los hogares en la población de origen haitiano? Estas preguntas están dentro de las que hasta ahora permanecen sin respuesta en la literatura académica sobre la población de origen haitiano en República Dominicana.

El objetivo de este artículo es analizar las principales características sociodemográficas de los inmigrantes haitianos ${ }^{1}$ en República Dominicana y de los dominicanos de padres haitianos, ${ }^{2}$ tomando en cuenta no sólo las configuraciones de los mercados de trabajo, sino también algunos elementos socioculturales presentes en los entornos en los que esta migración se desarrolla, así como ciertos factores demográficos. Es decir, consideramos que la migración haitiana a República Dominicana no responde únicamente a los factores económicos o laborales, sino también a los sociales y los demográficos. La estrategia analítica adoptada busca, por una parte, evidenciar los cambios y continuidades en los perfiles de los haitianos dividiéndolos de acuerdo con la duración de la estancia -los que tienen cinco o más años en República Dominicana (los antiguos) y aquellos que cuentan con una estancia menor a este lapso (los nuevos)-, resaltando las especificidades de los dominico-haitianos. En ocasiones también se comparan las características de ambos grupos con las presentadas por los dominicanos sin ascendencia haitiana. ${ }^{3}$ Por otra parte, se exploran los elementos contextuales, demográficos y del mercado laboral que ayudan a entender la situación que se presenta en los datos.

Para ello, utilizamos dos fuentes de datos: el censo más reciente de República Dominicana (el de 2010) (ONE, 2010) y la Encuesta Nacional de Inmigrantes en República Dominicana (ENI-2012) (ONE, 2012). Por su carácter universal y los tópicos que aborda, el censo constituye una fuente valiosa para estudiar las características de las poblaciones en su totalidad o

1 Consideramos como "inmigrante haitiano" a toda persona nacida en Haití y censada en República Dominicana en 2010. El número de personas con esta característica en el censo de 2010 fue de 311969 (ONE, 2010); a esta cifra añadimos 2387 personas que no contestaron la pregunta sobre su país de nacimiento, pero que indicaron que cinco años antes del censo vivían en Haití (asumimos que son inmigrantes haitianos que, por distintas razones, no quisieron indicar su país de nacimiento).

2 Las expresiones "dominicanos de padres haitianos", "dominicanos de ascendencia haitiana" o "dominico-haitianos" se usan de forma indistinta y se refieren a las personas nacidas en República Dominicana con uno o ambos progenitores nacidos en Haití.

3 Por "dominicanos sin ascendencia haitiana" o "dominicanos no descendientes" nos referimos a las personas nacidas en República Dominicana y que carecen de ascendencia haitiana inmediata; es decir, que ninguno de los progenitores nació en Haití, sin importar si tienen algún otro ascendiente que haya nacido en dicho país e independientemente de la o las nacionalidades de las que gocen. 
de los subgrupos que las conforman, entre otros usos. Sin embargo, para el caso que nos ocupa, no permite analizar adecuadamente a los dominicohaitianos ya que no pregunta por el lugar de nacimiento de los padres de los individuos. ${ }^{4}$ Esta particularidad dificulta conocer la diversidad de características que existe en esta subpoblación. Por esta razón, optamos por realizar el análisis sobre este segmento poblacional con datos de la ENI-2012, la cual contiene la información sobre el origen de los padres. Sin embargo, en los casos en que se compara alguna característica con los dominicanos sin ascendencia haitiana, se utilizó la información sobre los dominico-haitianos identificables en el censo para obtener datos de dicha categoría. Es decir, aunque no analizamos a los dominico-haitianos identificables en el censo, tal información sirvió para disociar a los dominicanos sin ascendencia haitiana de aquellos que sí tienen esta característica. ${ }^{5} \mathrm{El}$ artículo está dividido en tres apartados: el primero presenta brevemente la trayectoria de la migración haitiana a República Dominicana, el segundo analiza sus características individuales, y el último, las de los hogares.

\section{La migración haitiana a República Dominicana: un resumen histórico}

Los movimientos de personas en La Española -la isla que comparten Haití y República Dominicana- no son un fenómeno nuevo. Pero, en términos generales, los especialistas del tema consideran que los inicios del flujo actual de haitianos a Dominicana se remontan a principios del siglo XX, en consonancia con un notable empuje de la industria azucarera dominicana. En efecto, entre finales del siglo XIX y principios del XX, un grupo de empresarios cubanos y estadounidenses empezaron a invertir en el sector azucarero de República Dominicana (además del de Cuba y Puerto Rico) con el fin de aprovechar una serie de circunstancias internacionales y locales (Castor, 1983). Por su parte, Haití y otras islas del Caribe-Jamaica, San Cristóbal, San Vicente y demás-se insertaron en esa economía azucarera regional como proveedores de mano de obra, ya que los receptores de las inversiones carecían de suficientes trabajadores para cubrir la totalidad de las labores que requería el desarrollo del sector (Tejada, 2001; Del Castillo, 1978).

4 El censo capta únicamente a los dominico-haitianos que son hijos de jefes de hogares haitianos. No es posible identificar el origen haitiano en el caso de aquellos que tienen otro tipo de vínculo con el jefe o cuando ellos mismos son jefes.

5 Se asume que los dominico-haitianos no identificables no pueden alterar los resultados obtenidos para los dominicanos sin ascendencia haitiana. 
Por otro lado, buena parte del proceso de transformación de la industria azucarera dominicana se dio en un contexto político y social incitativo para la migración haitiana a República Dominicana. A principios del siglo XX, los dos países se encontraban ocupados militarmente por Estados Unidos -Haití: 1915-1934; Dominicana: 1916-1924-. En Haití, la introducción de empresas agrícolas estadounidenses por el ocupante -especialmente en la producción de frutas-condujo a que miles de campesinos fueran despojados de las tierras que laboraban, lo cual, junto con otras medidas a expensas del campesinado, desató una guerrilla rural contra la fuerza de ocupación (Moral, 1978; Castor, 1971; Gaillard, 1981). Para aliviarse de las revueltas y deshacerse del excedente de trabajadores agrícolas, los marines impulsaron la salida de numerosos campesinos haitianos hacia los ingenios azucareros de República Dominicana y Cuba (Castor, 1983), lo cual benefició también a los intereses estadounidenses en aquellos países, ya que los empresarios norteamericanos que controlaban buena parte de la industria azucarera necesitaban mano de obra barata.

Aunque durante esa época la migración haitiana suscitó inquietudes en Haití y en República Dominicana (Méroné, 2017; Moral, 1978), no cesó, pues gran parte de las fuerzas que la impulsaban estaban fuera del control de los dos estados y sus sociedades. Los inversionistas se habían percatado que, debido a la falta de mano de obra local, ${ }^{6}$ no podían prescindir de los trabajadores inmigrantes. Así, durante la década de los veinte, el volumen de trabajadores haitianos en República Dominicana creció tan rápido que al horizonte de los treinta reemplazaron a los migrantes procedentes de las otras islas (Del Castillo, 1978). Desde ese periodo, los haitianos consolidaron su presencia en las labores de baja calificación pero esenciales para la industria azucarera dominicana, de tal forma que en 1935 formaban las cinco sextas partes del conjunto de trabajadores de los ingenios (Castor, 1983). Los mecanismos sociales de expulsión en Haití -el sistema de tenencia de la tierra, el declive de la agricultura, la pauperización del campesinado (Moral, 1978)y de atracción en República Dominicana -la preferencia por la mano de obra haitiana por parte de los empresarios azucareros (Vega, 1988)- mantuvieron su dinamismo.

El crecimiento de la migración haitiana a República Dominicana durante los años treinta se vinculó también con la reacción de Cuba frente a la crisis económica de esa década. Como se sabe, la depresión de los treinta

6 Cabe mencionar que autores tales como Tejada (2001) y Del Castillo $(1978,2005)$ señalan que la escasez de mano de obra en el sector azucarero no sólo se debió a cuestiones demográficas, sino también a que, desde finales del siglo XIX, los campesinos dominicanos habían desertado de dicho sector debido a los bajos salarios que se pagaban. 
impactó fuertemente la economía estadounidense y las que gravitaban sobre su eje, como era (y sigue siendo en buena medida) el caso de las latinoamericanas y caribeñas. Precisamente, "la economía cubana fue una de las más afectadas por el episodio depresivo" (Madison, 1989, citado por Santamaría, 1995, p. 151), razón por la cual este país decidió adoptar medidas restrictivas para contener la llegada de trabajadores haitianos que se dirigían a sus ingenios (Castor, 1983; Moral, 1978). Alrededor de setenta mil haitianos fueron expulsados de Cuba, mismos que se redirigieron masivamente a República Dominicana, ya que no encontraron políticas de integración laboral en Haití, contribuyendo a engrosar el número de trabajadores de origen haitiano en el país vecino (Tejada, 2001; Castor, 1983).

Por otro lado, cabe resaltar que ese crecimiento migratorio se dio al margen de las controversias sobre la delimitación de la frontera entre Haití y República Dominicana, las cuales se resolvieron en 1936; sin embargo, el desenlace de ese diferendo territorial condujo al primer choque importante que experimentó la migración. De acuerdo con varios autores, el trazado de la frontera representa una de las causas principales de la matanza de miles de haitianos ${ }^{7}$ en 1937 en República Dominicana (Turits, 2002; Derby y Turits, 1993; Castor, 1983; Moya Pons, 1992). La línea divisoria oficial dejaba a varias comunidades con alta presencia haitiana en territorio dominicano, convirtiendo a una buena porción de la parte dominicana de la región fronteriza como una franja "culturalmente haitiana", que además estaba poco controlada por el gobierno central de Santo Domingo. Esa situación fue percibida como una amenaza contra la soberanía y la identidad nacional de República Dominicana, pues existe un antihaitianismo histórico y tajante en ese país, mismo que fue reavivado por el generalísimo Rafael Trujillo, quien fungió como presidente de la República en aquel entonces (Miranda, 2014; Turits, 2002; Castor, 1983). Según los autores, para erradicar esa "amenaza" y asentar la autoridad de su administración, el dictador -con la aprobación de una porción de las elites de la época (Hintzen, 2016; Turits, 2002)- ordenó la masacre en el marco del llamado plan de dominicanización de esa región, mismo que tuvo como objetivo eliminar a la población de origen haitiano de esas comunidades y reemplazarla por dominicanos sin ascendencia haitiana e inmigrantes blancos procedentes de otros países, así como implementar un plan de desarrollo en la frontera (Moya Pons, 1992; Vega, 1988; Price-Mars, 1953). Algunos autores sostienen que la masacre pudo haber sido motivada

7 No existe consenso sobre el número de haitianos, dominico-haitianos y haitiano-parecidos que fueron asesinados en los acontecimientos de 1937. Las cifras varían desde "varios cientos" hasta 35 000. Bernado Vega (1988), por ejemplo, ofrece 54 estimaciones distintas publicadas sobre el número de víctimas. 
también por preocupaciones personales de Trujillo en tanto que tenía que demostrar a las elites antihaitianas que su propio origen haitiano ${ }^{8}$ no representaría una debilidad para defender los intereses de República Dominicana frente a Haití y los haitianos (Hintzen, 2016; Peguero, 2004).

Pese a la matanza, las autoridades dominicanas de la época eran conscientes de la vitalidad de la mano de obra haitiana para hacer funcionar la industria azucarera, misma que se había convertido en el motor de la economía del país y generaba su principal producto de exportación. En 1952, la demanda de mano de obra llevó al gobierno de Trujillo a firmar un acuerdo con el gobierno haitiano para la contratación de trabajadores temporales para ese sector. Ese acuerdo se repitió cada cinco años y funcionó hasta 1986, pues desde mediados de la década de los setenta la industria azucarera empezó a presentar signos de debilidad, por lo que ya no era necesario, desde el punto de vista de sus dirigentes, seguir importando trabajadores (Lozano, 2005, 1998). Sin embargo, durante su aplicación esos acuerdos reforzaron el vínculo de la migración con el mercado de trabajo azucarero y el mercado agrícola más amplio, asegurando la disponibilidad de una mano de obra "adecuada" y maleable, conformada por hombres jóvenes, con baja escolaridad, procedentes de zonas rurales en su mayoría.

Aparte de la crisis de la industria azucarera, a partir de la década de los setenta ocurrieron diversos cambios en los dos países que afectaron el volumen, la composición del flujo y los segmentos laborales en los que se insertaban los inmigrantes. Los trabajadores haitianos empezaron a emplearse en cultivos no cañeros, tales como el café, el arroz, el tabaco, entre otros (Lozano, 1998). La crisis se había expandido al conjunto de la agricultura del país, agravando la situación de numerosos pequeños productores rurales, quienes migraron en volúmenes significativos hacia las ciudades o a Estados Unidos (Lozano, 1998, 2005). Esta situación ocasionó una mayor escasez de mano de obra nativa en varios cultivos, lo que favoreció la entrada de trabajadores haitianos y dominico-haitianos en ellos (Lozano, 2005). Posteriormente, los mismos participaron en la producción de otros productos como el plátano, la piña, el tomate, etc. (Báez y Lozano, 1985). Los haitianos han ampliado y consolidado su presencia en dichos cultivos -así como lo hicieron en tiempos anteriores para la producción de caña de azúcar-, de tal manera que, hoy en día, varios sectores de la agricultura dominicana dependen en gran medida de la mano de obra de origen haitiano (Peña, 2015).

8 De acuerdo con Derby (2009), citado por Hintzen (2016), la abuela de Trujillo era haitiana. 
Cabe mencionar que los cambios que se dieron en el sector agrícola dominicano durante la década de los setenta se produjeron en un contexto más amplio de transformación económica. A partir de esa época comenzó el proceso de terciarización de la economía dominicana, con el desarrollo de sectores como las zonas francas de exportación, las actividades industriales, el turismo, y los servicios (Ariza, 2004; Tejada, 2001). Aunque los inmigrantes haitianos no fueron insertados principalmente en esos sectores, ese nuevo dinamismo económico atrajo a mayores números de migrantes haitianos y con perfiles más diversos. De hecho, los cambios que empezaron a darse en los perfiles de los migrantes a partir de esa época animaron a algunos autores a hablar de una nueva inmigración haitiana a Dominicana, distinta a aquella que fue dirigida casi exclusivamente a la industria azucarera, o a la agricultura más ampliamente (Silié, Segura y Dore, 2002).

En cambio, del lado de Haití, durante la misma época, ocurrieron diversos acontecimientos que contribuyeron a empeorar la situación económica, política, social y ambiental, aumentando el número de personas que buscaban emigrar. Por ejemplo, entre finales de los setenta y principios de los ochenta, a causa de la presencia de la peste porcina, el gobierno haitiano, con el apoyo de los gobiernos de Estados Unidos, Canadá y México, y de algunas instituciones internacionales, decidió sacrificar al ganado de cerdos, los cuales fungían como el ahorro de los campesinos; ello acentuó la pobreza en las zonas rurales (Michel, 2010). En 1986, la caída de Jean-Claude Duvalier y del movimiento de dechoukaj ${ }^{9}$ que lo siguió, agravaron aún más la situación económica. Por otra parte, entre 1991 y 1994, el golpe de estado contra Jean Bertrand Aristide y el bloqueo comercial impuesto contra el país por la ONU y la OEA afectaron enormemente su economía, destruyendo miles de puestos de trabajo. Además, la serie de crisis políticas y catástrofes naturales que continuaron durante las décadas de los noventa y dos mil, que culminaron con el terremoto de enero de 2010, el brote de cólera y los sucesivos huracanes, hicieron que una proporción cada vez más importante de haitianos buscara salir del país. Una parte de ellos encontró en República Dominicana una tierra de acogida o una ruta para otros destinos.

En suma, durante su historia la migración haitiana a República Dominicana ha sido impulsada por distintas fuerzas, unas internas de cada país involucrado y otras externas a ambos. Sin embargo, el común denominador

9 Término en creole haitiano para designar las destrucciones ocasionadas por manifestantes, después de la caída de la dictadura de los Duvalier, de todo lo relacionado a ese régimen, incluso obras públicas, empresas o propiedades privadas cuyos dueños estaban ligados a la dictadura. El término se usa también para referirse a los mismos actos, generalmente perpetrados a la caída, por la fuerza, de otros gobiernos. 
sigue siendo el vínculo estrecho de la migración con configuraciones peculiares de los mercados laborales de Haití y de Dominicana, pese a que, durante las últimas décadas, las razones por las que los haitianos cruzan la frontera se han diversificado. Tal diversificación ha ocasionado cambios en la composición sociodemográfica de los migrantes, aunque sigue habiendo rasgos tradicionales en el colectivo. Como ya se mencionó en este artículo, proponemos analizar las características de los inmigrantes haitianos y de los dominico-haitianos tratando de poner de relieve no sólo sus vínculos con los mercados de trabajo nacionales, sino también los elementos de los sistemas socioculturales de ambos países que contribuyen a explicar la situación.

\section{Las características individuales}

\section{Estructura por edad y sexo}

Los datos referentes a la composición etaria muestran que los haitianos en República Dominicana están concentrados en edades laboralmente activas, específicamente entre 15 y 55 años; en consecuencia, la base y la parte superior de su pirámide poblacional son estrechas (Gráfica 1). Este dato es coherente con la idea de que la mayor parte de los haitianos que viven en República Dominicana migró en busca de oportunidades de trabajo. Esto no es una situación nueva, ya que, como se dijo con anterioridad, la migración haitiana a dicho país ha sido caracterizada por ser principalmente laboral, pese a que los motivos también se han diversificado en las recientes décadas. De esta manera, la concentración de la población en las edades activas conforma una continuidad en el flujo migratorio. De hecho, una encuesta de la Flacso-República Dominicana y la OIM en 2004 demostró que el móvil principal de la migración de Haití a Dominicana seguía siendo laboral. En efecto, la Encuesta sobre Inmigrantes Haitianos en República Dominicana (Flacso / OIM, 2004) encontró que el 74\% de los haitianos que migraron a ese país lo han hecho por razones de trabajo.

En relación con la estructura por sexo, los haitianos en Dominicana conforman un colectivo bastante masculinizado, con $62 \%$ de hombres en 2010 (Cuadro 1). En la Gráfica 1 se puede apreciar la brecha entre los porcentajes de hombres y mujeres a favor de los primeros tanto entre los antiguos migrantes como entre los nuevos, aunque con una amplitud menor en este subgrupo. Los antiguos tienen un porcentaje de mujeres diez puntos más alto que los nuevos (43 y 32.4\%, respectivamente, Cuadro 1 ), lo cual habla de 


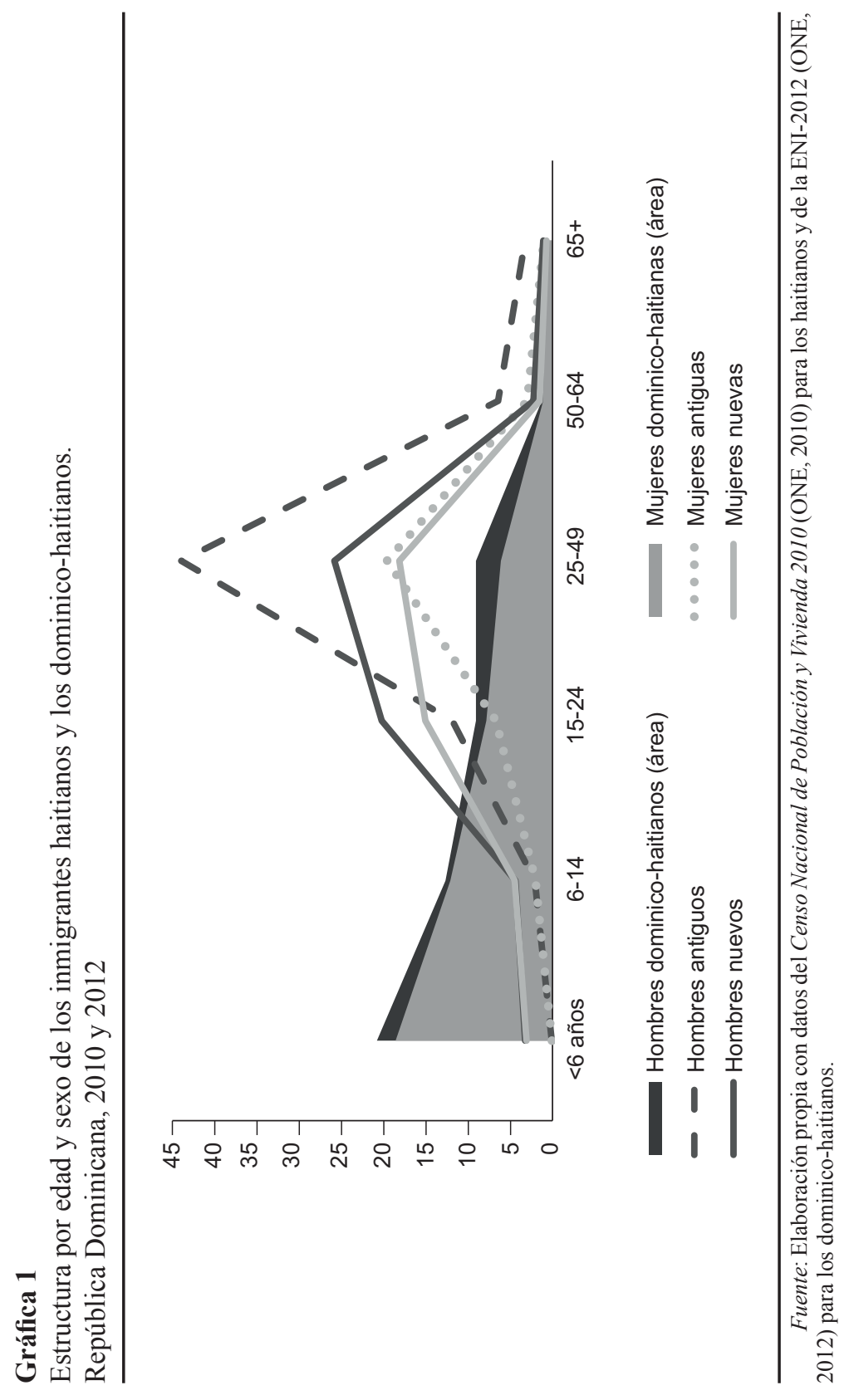




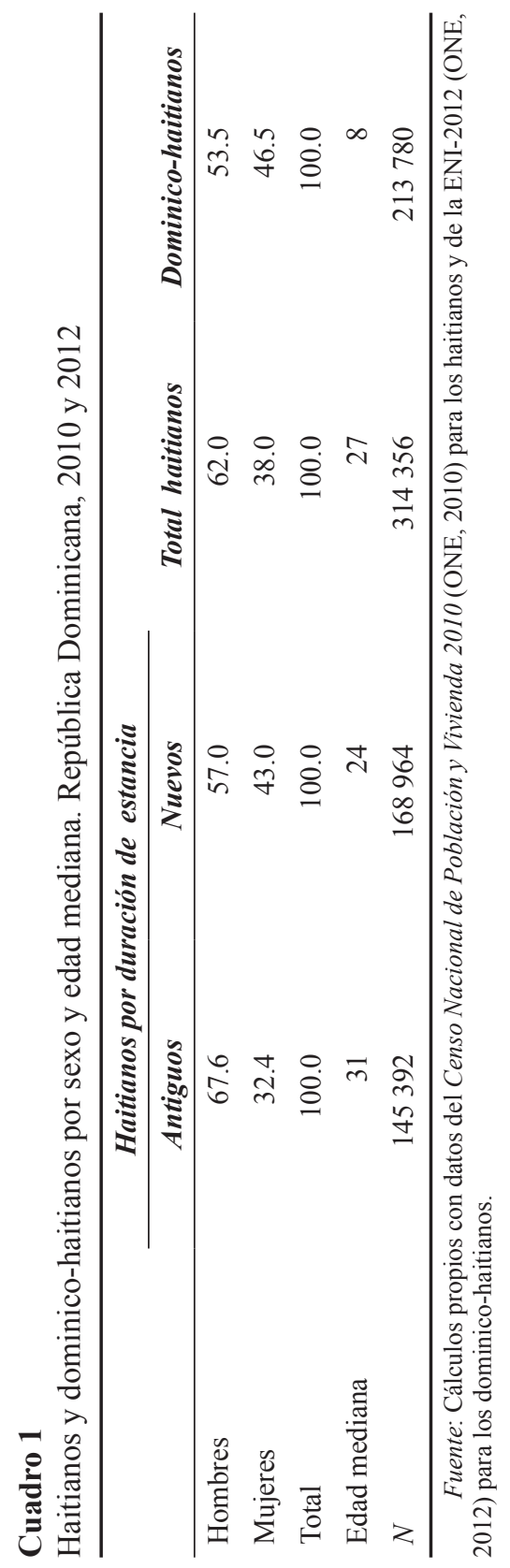


un proceso de feminización de la migración durante los años recientes. ${ }^{10} \mathrm{En}$ efecto, la Encuesta sobre los Inmigrantes Haitianos en República Dominicana (Flacso / OIM, 2004) encontró un nivel de sólo 22.4\% de mujeres en la población. Si los datos de esta encuesta son consistentes con los del censo, podría hablarse de un incremento muy acelerado de la proporción de mujeres entre los haitianos, pasando de $22.4 \%$ en 2004 a $38 \%$ del total de migrantes en 2010. En todo caso, el hecho de que en conjunto sigue existiendo una mayor proporción de hombres entre los migrantes, refleja la continuidad de la selectividad por sexo en la migración (Bidegain, 2012).

Diversos factores pueden explicar la persistencia de la selectividad por sexo entre los inmigrantes haitianos en República Dominicana. Uno de ellos es la orientación agrícola que ha tenido la migración durante varias décadas; de hecho, una parte significativa de los haitianos en ese país sigue laborando en dicho sector (Méroné, 2017). Como se sabe, en muchas culturas, incluyendo a la haitiana y la dominicana, las labores relacionadas con la agricultura están estereotipadas como masculinas. Además, la serie de acuerdos entre los dos países para la contratación de trabajadores haitianos para el sector cañero dominicano (1952-1986) privilegió a los hombres, lo que acentuó el carácter masculino del flujo migratorio y, por lo tanto, de la población inmigrante.

Otro factor explicativo de la sobrerrepresentación masculina entre los haitianos es la percepción negativa que se tenía en Haití, por lo menos hasta hace poco, respecto de la emigración de mujeres a República Dominicana. En diversos lugares de Haití se decía que esas mujeres iban a "lave boutèy", ${ }^{11}$ expresión en creole haitiano utilizada para referirse a la supuesta prostitución a la que se dedicarían una vez llegadas al territorio dominicano. Era también una manera (errónea) de decir que en ese país no existía otro trabajo para las haitianas más que el sexual. En muchos sectores de la población, esa percepción se convirtió en una presión social negativa contra la emigración femenina a República Dominicana. Aparte de los "trabajos masculinos" a

10 Obviamente no hay que olvidar que al ser, en promedio, más grandes que las recientes, las antiguas tienen una probabilidad de muerte más alta. También la probabilidad de retorno o la de migración subsecuente pueden ser más elevadas entre esta categoría.

11 También se dice "graje boutèy"; las dos expresiones son sinónimas. Se usan para referirse al trabajo de prostitución que supuestamente practican las haitianas que migran a República Dominicana. Se creía que era el único trabajo que existía para la mujer que va a ese país. En el mismo orden de ideas, en República Dominicana existe otra expresión utilizada por algunos sectores dominicanos para referirse a un supuesto atributo físico-sexual que tendrían las haitianas y dominico-haitianas (o toda mujer afrodescendiente) para aumentar el placer sexual del hombre: el "coco mordan" (literalmente, la vagina que muerde). Hace alusión a la vagina que, supuestamente, aprieta y chupa el genital masculino con movimientos rítmicos y ondulantes causando al hombre una eyaculación rápida y particularmente agradable (Vargas, 2010). 
los que se dirigían los migrantes haitianos, la percepción de que las mujeres tenían únicamente un rol sexual en ese país, sin duda tuvo un papel disuasivo para su emigración durante mucho tiempo.

En cambio, las posibles explicaciones de la feminización de la población haitiana en República Dominicana son múltiples. Por ejemplo, pueden radicar en los cambios ocurridos en la economía dominicana durante las últimas décadas a raíz de los cuales ciertos sectores como el turismo, los servicios y las zonas francas industriales adquirieron importancia. La creciente demanda de la fuerza de trabajo femenina que acompaña el desarrollo de estas actividades (Ariza, 2004) pudo atraer a mujeres haitianas, directa o indirectamente, para asumir tareas en hogares donde las dominicanas se encuentran involucradas en actividades extradomésticas. También, la feminización de la población migrante pudo originarse en una menor presión social en Haití contra la emigración de sus mujeres a República Dominicana, como señalamos anteriormente; esto combinado con el continuo deterioro de la economía haitiana (Lozano, 2005; Pascual Morán y Figueroa, 2005).

Por último, la feminización de la población haitiana en República Dominicana puede explicarse por una menor circularidad de los inmigrantes a raíz de la cesación de los acuerdos de contratación de trabajadores temporales en 1986 y las múltiples convulsiones políticas, sociales y ambientales en Haití. Los hombres unidos que antes estaban involucrados en movimientos pendulares podrían haber sentido menos interés para llevar a su pareja haitiana. A medida que la migración se vuelve más permanente, la necesidad de establecerse con la familia puede hacerse más intensa para esos hombres, provocando una mayor feminización de la población. De hecho, según nuestros cálculos, con datos del censo de 2010, la mayoría de las mujeres recién llegadas de 15 y más años de edad están unidas (68.4\%), aunque no es posible determinar si su migración está relacionada con la reunificación familiar.

En cuanto a los dominicanos de ascendencia haitiana, presentan una estructura por edad y sexo bastante distinta de la de los migrantes. La Gráfica 1 permite dimensionar la juventud de este subgrupo, caracterizado por una alta concentración en edades menores a 15 años; de hecho, su edad mediana, de acuerdo con datos de la ENI-2012, fue de ocho años (Cuadro 1). La juventud de los dominico-haitianos puede originarse, entre otras razones, en la feminización reciente de la población inmigrante. ${ }^{12} \mathrm{El}$ hecho de

12 La feminización reciente de la población inmigrante representa solamente una parte de la explicación; también hay dominico-haitianos con padre haitiano y madre nacida en República Dominicana. Según los datos de la ENI-2012, éstos representan el 20.5\% del colectivo (cálculos propios). 
que la migración haya sido masculinizada y circular durante mucho tiempo, dejaba posibilidades limitadas para la formación de una población dominicohaitiana importante y de larga data, pues los hijos de los inmigrantes solían nacer preferentemente en Haití. La mayor proporción de mujeres en la población inmigrante en tiempos recientes, asociada con su alta tasa de unión, puede explicar, en gran medida, que hayan nacido más personas de padres haitianos en Dominicana durante los últimos años, dando lugar a una población dominico-haitiana particularmente joven.

Otra diferencia entre los dos grupos reside en la composición por sexo. Las mujeres representan casi la mitad de los dominico-haitianos (46.5\%), lo cual contrasta notablemente con los inmigrantes. Por un lado, tenemos un grupo masculinizado (hasta el año 2010) y relativamente adulto, y por el otro, un grupo mayormente joven y con proporciones parecidas de hombres y mujeres. Las disimilitudes observadas en la composición por edad y sexo de los dos grupos reflejan las diferencias de los procesos de los que resultan. Siendo migrantes, los haitianos han sido sometidos a diferentes procesos de selectividad (por edad, sexo, escolaridad y demás), mientras que los dominicanos de ascendencia haitiana nacieron en República Dominicana, y consecuentemente están exentos de los procesos por los que transitaron sus padres. En cambio, al ser hijos de al menos un haitiano, su volumen y composición etaria son el resultado de factores propios de los migrantes, como pueden ser la intensidad y el tiempo de ocurrencia de la feminización de la migración, la etapa del ciclo de vida en que los migrantes se encuentran en el momento de migrar a República Dominicana, o bien de su patrón de fecundidad.

\section{Lugar de residencia}

En consonancia con otros estudios (ONE, 2009; Silié, Segura y Dore, 2002), los datos del censo confirman que el predominio de la residencia rural entre los migrantes haitianos en República Dominicana pertenece al pasado. Casi seis de cada diez de ellos vivían en zonas urbanas en 2010 (Cuadro 2). Además, los recién llegados parecen estar estableciéndose directamente en las ciudades, pues el porcentaje de personas que viven en alguna urbe es 10 puntos porcentuales mayor entre los nuevos, en comparación con los antiguos (64 y 53.6\% respectivamente). Asimismo, las mujeres presentan niveles más elevados de residencia urbana que los hombres (65.2\% contra 55.5\%). Pero, aun así, los niveles de residencia urbana entre los haitianos están por debajo 


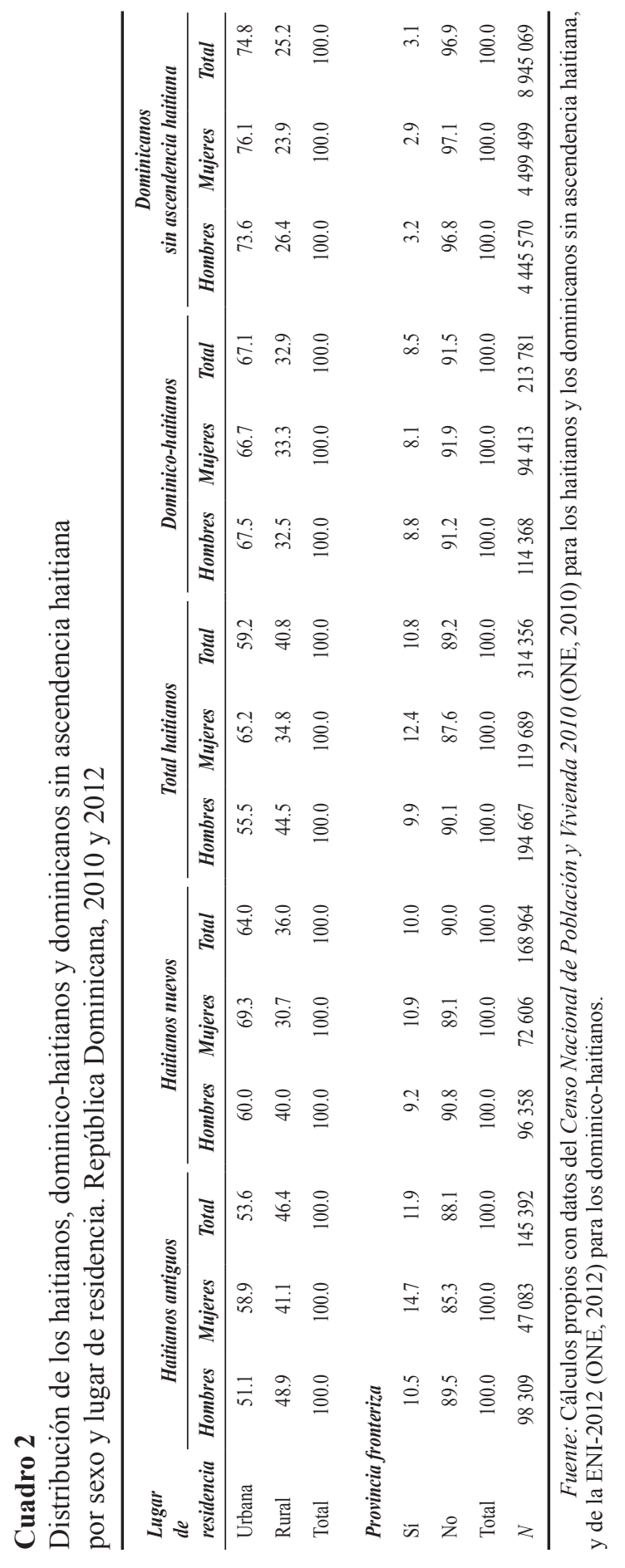


de los correspondientes a los dominico-haitianos (67.1\%) o los dominicanos sin ascendencia haitiana $(74.8 \%)$.

Así como la tendencia al aumento del componente femenino, la urbanización de la población migrante parece responder a la diversificación de la economía dominicana. Como señalamos anteriormente, desde la década de los setenta la industria azucarera dominicana empezaba a presentar signos de debilidad, al mismo tiempo que el país comenzaba a experimentar una diversificación de sus actividades productivas (Ariza, 2004). Los nuevos sectores generadores de empleos, tales como el turismo, la construcción y las zonas francas, suelen ubicarse predominantemente en zonas urbanas o cerca de éstas. Aunque no estén mayoritariamente insertados directamente en ocupaciones relacionadas con estas actividades económicas, las labores paralelas que generan pueden constituir una fuerza de atracción importante y contribuir a explicar la residencia predominantemente urbana de los inmigrantes. Es decir, la transición residencial de los inmigrantes haitianos parece relacionarse positivamente con la transición económica de República Dominicana. Por otro lado, el componente cada vez más importante de estudiantes entre los migrantes sin duda afecta la predominancia urbana de la población, pues la mayor parte de esos jóvenes vive en ciudades como Santiago y el Gran Santo Domingo (Pierre, 2013).

Otro aspecto relevante en relación con el lugar de residencia de los inmigrantes haitianos es su ubicación o no en la zona fronteriza. ${ }^{13}$ Como ya se mencionó, la frontera entre Haití y República Dominicana ha cobrado una importancia especial en las relaciones entre los dos países y en la migración de los haitianos. Recordemos que una de las causas de la masacre de 1937 fue, según varios autores, la voluntad de las autoridades dominicanas de la época de erradicar la presencia haitiana en las localidades circundantes a la frontera, en tanto era considerada como una amenaza para la identidad y la soberanía dominicanas. Sin embargo, debido a la cercanía, la porosidad de la frontera, la mayor facilidad para obtener algunos servicios básicos en la parte dominicana y las oportunidades laborales que ofrecen algunas ciudades de esta zona (Riveros, 2014; Pascual Morán y Figueroa, 2005; Castor, 1983), la región fronteriza representa una zona tradicional de llegada de una parte de la migración haitiana. De hecho, estudios sobre comunidades dominicanas cercanas a la frontera documentan la existencia de una cultura rayana ${ }^{14}$ caracterizada por

13 Por cuestiones técnicas, consideramos a las cinco provincias dominicanas colindantes con Haití como "zona fronteriza". Sin embargo, reconocemos que los procesos fronterizos se desarrollan en un gradiente, de tal manera que pueden existir áreas dentro de una misma unidad territorial fronteriza (una provincia, por ejemplo) en las que éstos son más o menos relevantes.

14 De la raya (del español dominicano para designar la línea fronteriza). El adjetivo $r a-$ 
el mestizaje de elementos de las idiosincrasias de los dos pueblos que comparten la isla, entre otros rasgos (Victoriano-Martínez, 2010).

En concordancia con lo anterior, los datos muestran que la región fronteriza capta un porcentaje considerable de los inmigrantes haitianos (10.8\%), aunque ésta constituye una de las zonas más pobres de República Dominicana (Alfonso y Cedano, 2005). Este porcentaje traduce también una mayor presencia relativa de los haitianos que de los dominicanos sin ascendencia haitiana en las provincias fronterizas (10.8\% contra 3.1\%) (Cuadro 2). En cuanto a la duración de la estancia, no encontramos diferencias significativas en el asentamiento en la frontera entre los inmigrantes antiguos y los nuevos (11.9 y 10\% respectivamente). En cambio, existe una ligera diferencia por sexo en el asentamiento fronterizo a favor de las mujeres $(9.9 \%$ para los hombres contra $12.4 \%$ para las mujeres), lo cual puede deberse a la preponderancia de las actividades de comercio (minorista) en esta región, especialmente en las ciudades de Dajabón, Comendador, Jimaní y Pedernales. También existe una ligera diferencia entre los migrantes y los dominicohaitianos ( 8.5 y $10.8 \%$ respectivamente).

Una de las explicaciones de las diferencias en el asentamiento fronterizo entre la población de origen haitiano y los dominicanos sin ascendencia haitiana es que la parte occidental de República Dominicana (contigua a la frontera) ha sido una zona tradicionalmente despoblada. Según Alfonso y Cedano (2005), la dominicanización realizada por la administración de Trujillo (en 1937) fue el único proyecto de desarrollo específico que ha planteado el estado dominicano en esta zona. Ello deriva en que esta región del país presenta índices mayores de pobreza, contribuyendo en volverla poco alentadora para el impulso demográfico, especialmente para los dominicanos. En cambio, por las razones mencionadas anteriormente, una parte de los haitianos considera a esta zona como un lugar apropiado para asentarse, lo cual ocasiona que en las comunidades ubicadas cerca de la parte dominicana de la frontera la proporción de haitianos sea más alta que en otros lugares.

yano se refiere a personas que nacen o viven en la zona fronteriza, y que al menos uno de sus padres es haitiano; pero el término ha sido extendido a toda la población de la región (Victoriano-Martínez, 2010). 


\section{Escolaridad}

Para el análisis de la escolaridad dividimos a la población en dos partes. Primero consideramos el último nivel que alcanzaron las personas de 25 años y más de edad, y luego analizamos la asistencia escolar entre los que están en edad escolar. Cabe precisar que, aunque la asistencia escolar suele estudiarse hasta los 19 años, decidimos incluir a las personas de 20 a 24 años ya que, por una parte, tanto en Haití como en Dominicana los retrasos acumulados en el ciclo escolar hacen que personas de este grupo de edad -e incluso con más edad- sigan asistiendo a programas escolares. Por otro lado, los datos no permiten separar la población por tipo de escolaridad (escuela o universidad); por lo tanto, la asistencia escolar incluye la matrícula universitaria. Entonces, el análisis de la asistencia escolar se realiza para personas de 6 a 24 años.

Para realizar un análisis más detallado de la asistencia escolar, dividimos a los individuos de 6 a 24 años en tres subgrupos: 6 a 14, 15 a 19 y 20 a 24 años. A través del primer subgrupo buscamos investigar el nivel de escolarización entre los niños, mientras que con el segundo pretendemos dar cuenta de la matrícula en niveles escolares más avanzados; además, este último grupo ofrece la posibilidad de aproximar el abandono escolar relacionado con el trabajo, ya que, como se sabe, este grupo (15 a 19 años) representa un punto de inflexión importante en la primera inserción laboral entre los jóvenes. Por último, el grupo de los 20 a 24 años permite aproximarse a los retrasos en el sistema escolar, así como a la matrícula universitaria.

Los datos respecto a la escolaridad de las personas de 25 años y más de edad muestran que, en términos generales, los haitianos presentan niveles particularmente bajos. En ambos sexos, más del $40 \%$ del total de los inmigrantes no tiene ningún nivel (Gráfica 2). Este indicador es aún mayor entre los antiguos, especialmente en las mujeres, pues la mitad no tiene escolaridad. Por otro lado, entre los haitianos que cuentan con algún nivel escolar, aquellos que tienen la primaria conforman el grupo más importante, mientras que los que tienen secundaria o más forman el grupo minoritario. Este panorama contrasta significativamente con el presentado por los dominicanos sin ascendencia haitiana del mismo grupo de edad, entre quienes el nivel sin escolaridad se establece en alrededor de $10 \%$, y más del $50 \%$ cuentan con secundaria y más.

Pero, aun así, se pueden observar diferencias en la duración de la estancia entre los haitianos. Entre los nuevos, los porcentajes de personas con niveles de secundaria y universitaria son más altos. Esta situación puede 


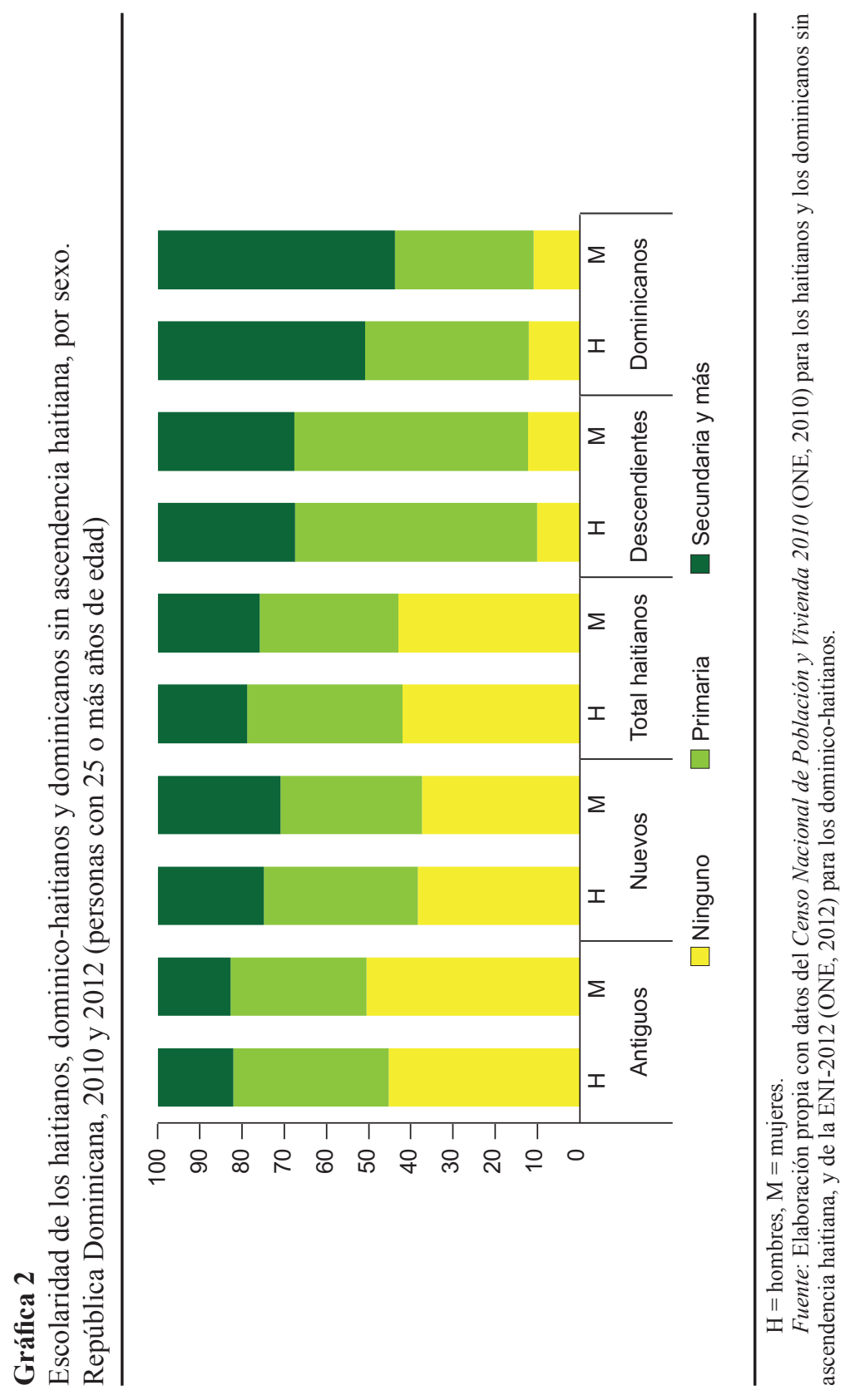


explicarse por la mejora en la educación en Haití y por el hecho de que, desde los años dos mil, un número creciente de jóvenes haitianos se matriculan en escuelas y universidades dominicanas (Pierre, 2013). No existen estudios específicos sobre el retorno entre este último grupo de personas a Haití o su redirección a otros países; sin embargo, es muy probable que una parte de ellos se queden en República Dominicana después de concluir sus estudios. En todo caso, la situación educativa de la población haitiana en República Dominicana refleja tanto el bajo nivel educativo en el país de origen, ${ }^{15}$ como una continuidad de las características de las personas que tradicionalmente han migrado a este país; es decir, personas procedentes de zonas rurales con baja o sin escolaridad.

Por su parte, los dominico-haitianos presentan una mejora notable en los niveles de escolaridad en comparación con los inmigrantes haitianos. En efecto, tienen porcentajes menores de sin escolaridad y mayores porcentajes de personas con escolaridad primaria. Sin embargo, en cuanto al nivel de secundaria y más, tienen rangos parecidos a los de los haitianos de reciente arribo, muy bajos en comparación con los porcentajes registrados por los dominicanos sin ascendencia haitiana para este grado de escolaridad. Es decir, aunque tienen niveles de analfabetismo parecidos a los dominicanos sin ascendencia haitiana (alrededor de 10\%), la mayoría no alcanzan la escolaridad que les proporcione la calificación necesaria para ser competitivos en el mercado laboral. Esta situación puede deberse a que muchos de los dominicanos de ascendencia haitiana (de estas edades) nacieron y crecieron en zonas rurales o bateyes, ${ }^{16}$ donde el acceso a niveles superiores de la educación formal era (y sigue siendo) limitado.

En lo que se refiere a la asistencia escolar, en ambos sexos, los haitianos de 6 a 24 años presentan niveles menores que sus pares dominico-haitianos y dominicanos sin ascendencia haitiana (Gráfica 3). Por ejemplo, mientras que aproximadamente $85 \%$ de los dominico-haitianos y $92 \%$ de los dominicanos sin ascendencia haitiana de 6 a 14 años asiste la escuela, sólo $55 \%$ de los niños haitianos de las mismas edades se encontraban matriculados en una institución escolar en 2010. Esta brecha a favor de los dominico-haitianos y

15 De acuerdo con los datos de la encuesta haitiana Enquête Mortalité, Morbidité et Utilisation de Services, V (EMMUS-V, 2012) (Cayemittes et al., 2013), el porcentaje de personas sin escolaridad en Haití se establece en alrededor de $25 \%$. Este indicador es más alto en las zonas rurales y entre las generaciones nacidas antes de 1990 .

16 El batey es un "campamento de reproducción de fuerza de trabajo inmigrante, que permite mantener a este grupo humano segregado del resto de la nación [...]" (Lozano, 2005). Tejada (2001) señala que aunque el término batey está asociado a la caña de azúcar, en tiempos recientes empezó a ser utilizado para referirse a comunidades cercanas a otros cultivos, o a zonas urbanas marginales con una concentración importante de haitianos y dominico-haitianos. 


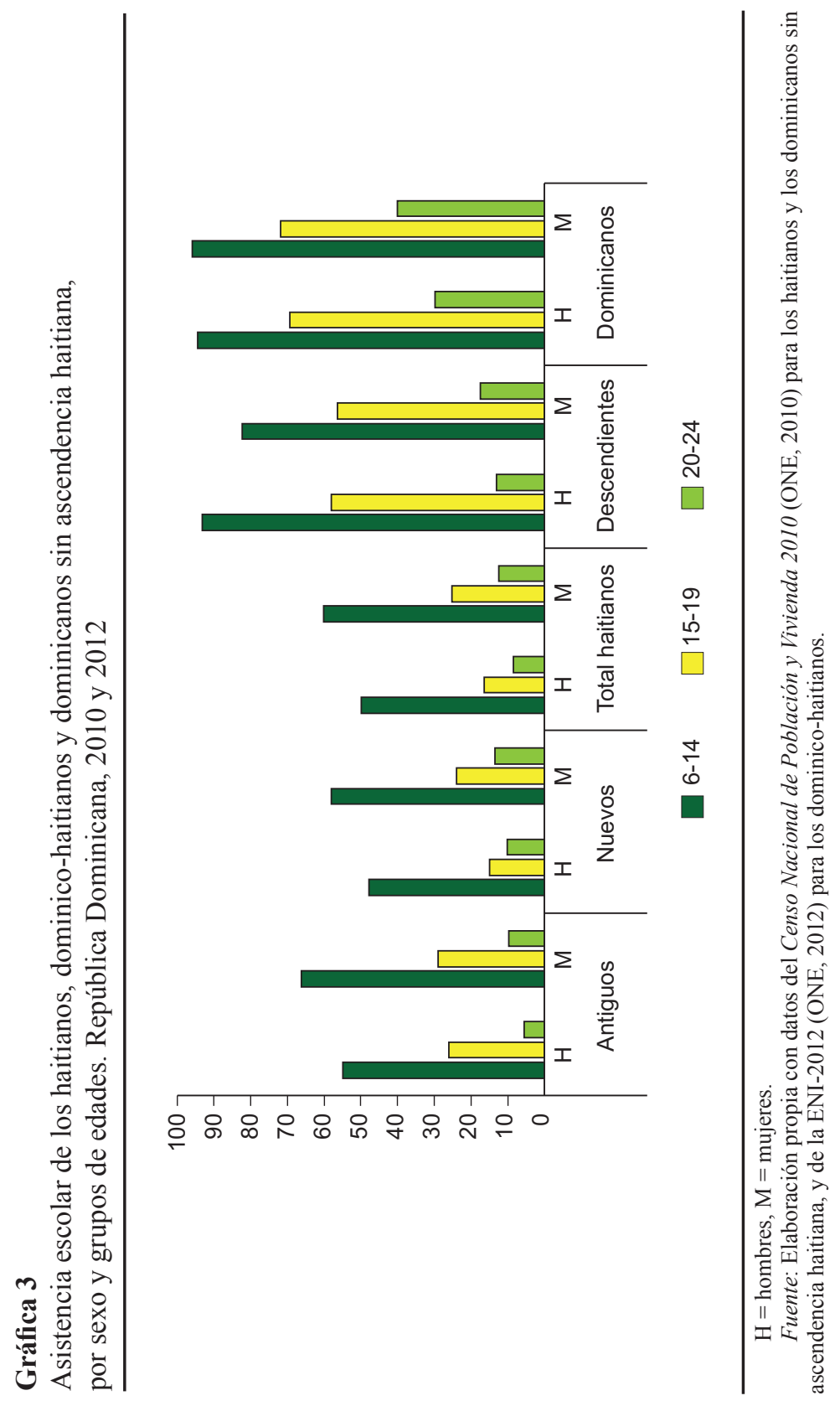


los dominicanos sin ascendencia haitiana se observa también entre los jóvenes de 15 a 19 y de 20 a 24 años, aunque con amplitudes distintas. Tales diferencias pueden deberse a las condiciones socioeconómicas, en promedio más precarias de los hogares inmigrantes, al carácter laboral de la migración y al menor dominio del español entre los miembros del colectivo haitiano. Por otro lado, entre los haitianos, los nuevos presentan menores niveles de asistencia escolar que sus compatriotas antiguos en los grupos de 6 a 14 y de 15 a 19 años (Gráfica 3). Esto puede ser el reflejo de diferencias en el dominio del español o de un menor conocimiento del sistema educativo dominicano entre los nuevos, o ambas situaciones. En cambio, los nuevos presentan niveles de asistencia escolar más altos en la categoría de 20 a 24 años. Esta situación puede deberse, en parte, a la migración con fines estudiantiles de algunos jóvenes a República Dominicana.

Aparte de las diferencias señaladas entre los diferentes grupos, la Gráfica 3 permite observar una reducción significativa de la asistencia escolar de un grupo de edad a otro en ambos sexos y entre los tres grupos étnico-nacionales. Entre los haitianos, la transición de 6 a 14 y de 15 a 19 años representa un punto importante en la tendencia de muchos a discontinuar sus actividades escolares. Esta transición corresponde a la entrada de los jóvenes a la población en edad económicamente activa. Es muy probable que estos cambios en la asistencia escolar reflejen un cambio de actividad entre quienes entran al mundo laboral a partir de los 15 años, o migraciones con fines laborales a partir de esa edad. En relación con estas últimas, podemos apreciar una mayor reducción de la asistencia escolar entre los nuevos de 15 a 19 años en comparación con los antiguos del mismo grupo de edad. Es decir, no hay que ilusionarse, aunque los volúmenes de jóvenes que migran con fines educativos se va incrementando en la población, la parte que realiza el desplazamiento con otros motivos, especialmente el laboral, sigue siendo importante. En cuanto a los dominico-haitianos y los dominicanos sin ascendencia haitiana, la intensidad en la reducción de la asistencia escolar es mayor al pasar de 15-19 a 20- 24 años en comparación con los haitianos, aunque es menor entre los dominicanos no descendientes de haitianos que aquellos que sí lo son. Si esta tendencia fue igual entre generaciones anteriores, podría explicar también los niveles de escolaridad observados en la Gráfica 2 para las personas de 25 años y más de edad. Es decir, los dominicanos sin ascendencia haitiana pasarían más tiempo en la escuela que los dominico-haitianos, y éstos, a su vez, estudiarían más tiempo que los haitianos, inclusive más que aquellos que llegaron a República Dominicana antes de los seis años. En otro estudio se encontró que los niveles de escolaridad afectan los indicadores laborales entre los tres grupos con mayores desventajas para los haitianos; es 
posible que estas desventajas sigan vigentes o se reduzcan muy poco en el futuro, dadas las diferencias en la asistencia escolar en las generaciones actuales y los otros factores que intervienen en la integración de la población de origen haitiano en República Dominicana (Méroné, 2017).

\section{Características seleccionadas de los hogares}

En esta sección analizamos las características de los hogares haitianos, de dominico-haitianos y de dominicanos sin ascendencia haitiana. Nos referimos con hogares haitianos a aquellos que son dirigidos por al menos una persona nacida en Haití, ya sea el jefe / la jefa o su cónyuge, independientemente del lugar de nacimiento de los demás integrantes o si comparten lazos de parentesco o no. El mismo criterio se usó para determinar los hogares de los dominicanos sin ascendencia haitiana y de los dominico-haitianos; es decir, que al menos uno de los jefes haya nacido en República Dominicana en el caso de los primeros, o que al menos uno de los jefes corresponda a nuestra definición de dominico-haitianos para los segundos. Nos limitamos a analizar tres características de los hogares: el sexo y la edad de los jefes, y la estructura o tipo de hogar. Estas características fueron elegidas por su relevancia en poner en evidencia los contextos socioculturales que enmarcan los hogares, y en determinar las etapas del ciclo de vida en que se encuentran y sus posibles implicaciones para el futuro de la migración.

De acuerdo con los datos del Cuadro 3, la mayoría de los hogares haitianos están encabezados por hombres (80.4\%). Los hogares de dominicanos sin ascendencia haitiana también registran un porcentaje alto, pero menor, de liderazgo masculino (61.5\%), mientras que sólo la mitad de los dirigidos por algún dominico-haitiano tiene a un hombre como jefe (50.5\%). Si bien el alto porcentaje de hogares haitianos con jefatura masculina se debe a que están conformados en su mayoría por personas que proceden de un contexto en que los hogares están fuertemente marcados por esta característica, ${ }^{17}$ también resulta de la composición por sexo de la población y de los tipos de arreglos residenciales que existen en ella. Como ya se mencionó, debido a la selectividad por sexo, la población haitiana en República Dominicana presenta un alto nivel de masculinización. Además, los datos sugieren que una parte importante de los hombres haitianos migran sin su familia y, al contrario de lo que se observó en otros contextos (Glick y Van Hook, 2011;

17 Según los datos de la EMMUS-V 2012, en Haití 60\% de los hogares están encabezados por hombres.

Estudios Demográficos y Urbanos, vol. 34, núm. 2 (101), 2019, pp. 269-300 doi: http://dx.doi.org/10.24201/edu.v34i2.1773 
Liversage y Jakobsen, 2010), una proporción considerable de ellos vive solo, contribuyendo a engrosar los niveles de jefatura masculina de los hogares. De hecho, como veremos más adelante, uno de cada cinco de los hogares haitianos es de tipo unipersonal, de los cuales el $87.2 \%$ está formado por hombres (cálculos propios). Otra explicación del elevado porcentaje de hogares de haitianos con jefatura masculina radica en los contextos socioculturales y socioeconómicos en que se desenvuelven; tanto Haití como República Dominicana son países marcados por una división sexual del trabajo en la que los hombres son los que principalmente cumplen con el rol de proveedores económicos de las unidades domésticas; por lo tanto, son los que más juegan el papel de jefe de hogar y, en consecuencia, son declarados como tal en los censos y las encuestas.

Con respecto a la edad de los jefes, más de la mitad de los hogares haitianos son dirigidos por personas de menos de 35 años (58\%); el 34.4\% por personas de entre 35 y 59 años, mientras que los dirigidos por personas de 60 años y más forman sólo el 7.6\%. Esta estructura por edad de la jefatura de los hogares haitianos contrasta con la de los hogares de dominicanos sin ascendencia haitiana, entre los cuales más de la mitad son encabezados por personas de 35 a 59 años (51.4\%); sólo el $27 \%$ de los jefes dominicanos tenían menos de 35 años. Estos datos sugieren que la mayoría de los hogares haitianos se ubica en las etapas de inicio y de expansión en el ciclo de vida del hogar; es decir, buena parte de ellos puede tener niños pequeños o en edad escolar. También es posible que los jefes y/o cónyuges tengan niños menores que se quedaron en Haití, los cuales pueden considerarse como posibles candidatos a la migración hacia Dominicana en el marco de los procesos de reunificación familiar. En cuanto a la edad de los jefes dominico-haitianos, nuevamente se refleja una estructura por edad joven y los arreglos residenciales que predominan entre ellos. Como veremos posteriormente, aparte de su juventud, el alto porcentaje de hogares unipersonales entre este grupo puede explicar esta composición por edad de los jefes. En efecto, más de seis de cada diez hogares dirigidos por dominicanos de ascendencia haitiana tenían un jefe menor a 35 años en 2012; los jefes que tenían entre 35 y 59 años representaban $31 \%$, mientras que los mayores de 59 años dirigían menos de $10 \%$ de los hogares.

Por otro lado, en lo que se refiere al tipo de hogar, contrariamente a lo que podría pensarse, el más común entre los hogares haitianos es el nuclear, ${ }^{18}$ con más del $40 \%$ (Cuadro 3); esto es 11 puntos porcentuales menor al nivel

18 Agrupa a núcleos conyugales sin o con hijos, o familias monoparentales sin la presencia de otros familiares o no parientes. 


\section{Cuadro 3}

Características seleccionadas de los hogares, según la composición étnico-nacional. República Dominicana, 2010 y 2012

\begin{tabular}{lccc}
\hline & \multicolumn{2}{c}{ Composición nacional del hogar } \\
\cline { 2 - 4 } Características & Haitianos & $\begin{array}{c}\text { Dominico- } \\
\text { haitianos }\end{array}$ & $\begin{array}{c}\text { Dominicanos } \\
\text { sin ascendencia } \\
\text { haitiana }\end{array}$ \\
\hline Sexo del jefe de hogar & & & \\
Hombres & 80.4 & 50.5 & 61.5 \\
Mujeres & 19.6 & 49.5 & 38.5 \\
Total & 100.0 & 100.0 & 100.0 \\
Edad del jefe & & & 27.0 \\
$<35$ años & 58.0 & 61.0 & 51.4 \\
De 35 a 59 años & 34.4 & 31.0 & 21.6 \\
60 y más años & 7.6 & 8.0 & 100.0 \\
Total & 100.0 & 100.0 & \\
Estructura del hogar & & & 53.2 \\
Nuclear & 42.1 & 24.9 & 14.4 \\
Unipersonal & 20.4 & 23.8 & 29.4 \\
Extendido & 26.0 & 26.4 & 2.4 \\
Compuesto & 6.5 & 22.0 & 0.6 \\
No pariente & 5.0 & 2.9 & 260.0 \\
Total & 100.0 & 100.0 & 373 \\
$N$ & 913 & 267 & \\
\hline Fuente: Cán & & & \\
\hline
\end{tabular}

Fuente: Cálculos propios con datos del Censo Nacional de Población y Vivienda 2010 (ONE, 2010) para los haitianos y los dominicanos sin ascendencia haitiana, y la ENI-2012 (ONE, 2012) para los dominico-haitianos.

de hogares nucleares registrados entre los dominicanos sin ascendencia haitiana (42.1\% contra 53.2\%). Lo anterior sugiere que una parte significativa de los haitianos en República Dominicana son proclives a radicarse en este país o a quedarse por un tiempo relativamente largo, pues la presencia de la familia per se, las dinámicas que genera y las responsabilidades que conlleva -especialmente cuando hay la presencia de niños o niñas en edades escolares-, pueden dificultar migraciones posteriores, incluso el retorno (voluntario) al país de origen. De hecho, estudios realizados en otros con- 
textos demuestran que existe una selectividad negativa para el retorno entre los migrantes que viven en familia, siendo quienes viven en hogares unipersonales o fuera de una unión conyugal los más propensos al retorno (Koolhas, 2015; Koolhas y Nathan, 2013).

También existen porcentajes significativos de hogares extendidos ${ }^{19} \mathrm{y}$ unipersonales entre los inmigrantes haitianos (26.0 y $20.4 \%$ respectivamente); no obstante, no son muy disimilares a los encontrados entre los hogares de dominicanos sin ascendencia haitiana (29.4 y 14.4\%). Como se documentó en otros contextos (Glick y Van Hook, 2011; Menjívar, 2000; Wright, Caspi, Moffitt y Silva, 1998), parece que, entre otras funciones, los hogares extendidos entre los haitianos y los dominicanos sin ascendencia haitiana actúan como mecanismos de solidaridad con familiares que por alguna razón -desempleo / subempleo, estudio, discapacidad, enfermedad, vejez u otra-no disponen de fuentes de ingresos o de fuentes estables, frecuentes o suficientes. De hecho, en otra investigación, Méroné (2017) encontró que existe una asociación negativa entre la pertenencia a un hogar extendido y la propensión a participar en el mercado de trabajo en los dos grupos.

Por último, llama la atención que entre los hogares dirigidos por los dominico-haitianos haya un nivel tan importante de hogares unipersonales (23.8\%), cuando se sabe que la mayor parte de ellos son jóvenes (Gráfica 1 y Cuadro 1); más aún, el porcentaje de hogares de este tipo entre los dominicanos con algún padre haitiano supera el de la población migrante. En cambio, registran un bajo porcentaje de hogares nucleares (24.9\%) en comparación con los otros dos grupos. ¿Cómo explicar un nivel tan alto de dominico-haitianos que viven solos a pesar de la juventud de este conjunto? ¿Se debe esto a conflictos intrafamiliares o a la deportación de sus padres a Haití? ¿Será ello la explicación del nivel bajo de hogares nucleares que se registra en este grupo? De ser así, ¿no tienen otros familiares con quienes vivir? En cualquier caso, los datos sobre la estructura del hogar entre los dominico-haitianos merecen ser corroborados y profundizados en estudios futuros. Finalmente, como era de esperarse, los hogares compuestos ${ }^{20}$ y los de no parientes ${ }^{21}$ son los menos frecuentes entre los tres grupos.

19 Aquellos en que, aparte de cónyuges e hijos, se pueden encontrar abuelos, nietos, tíos $\mathrm{u}$ otros integrantes de la parentela.

20 Son hogares en que, además de personas con lazos de parentesco, corresiden personas sin estos lazos.

${ }^{21}$ Son hogares conformados por personas que no comparten ningún vínculo de parentesco. 


\section{Conclusión}

A través del presente artículo se ha podido evidenciar que los inmigrantes haitianos en República Dominicana no forman un grupo sociodemográfico uniformizado, sino que entre ellos se encuentran perfiles diversos de acuerdo con dos ejes principales: la duración de la estancia y el sexo. Esto responde no sólo a las configuraciones diferenciadas de los mercados laborales nacionales, sino también a los contextos socioculturales de los dos países y a la propia dinámica migratoria. En cuanto a los dominico-haitianos, forman un grupo claramente distinto, pero con características resultantes de los rasgos demográficos de los haitianos, como son la feminización reciente de la migración y la etapa del ciclo de vida en que se encuentra buena parte de los integrantes del colectivo.

Resulta claro entonces que el rostro de la población de origen haitiano en Dominicana ha estado cambiando durante las últimas décadas y probablemente continúe esta tendencia. Más aún, una parte de esta población es susceptible de radicar por tiempos relativamente largos en dicho país, lo cual, en caso de suceder, puede conllevar implicaciones determinantes en el futuro de la migración Haití-República Dominicana, en la naturaleza de los lazos entre la diáspora haitiana en Dominicana y la población no migrante de Haití, y más ampliamente, en las relaciones entre los dos países. Esta posibilidad plantea para los dos estados involucrados la necesidad de definir mecanismos armonizados de gestión de los flujos, y resolver los problemas de documentación de los inmigrantes y los vinculados con la nacionalidad de sus hijos nacidos en República Dominicana. También pondrá al Estado y a la sociedad dominicanos ante el reto de demostrar su capacidad y apertura para respetar los derechos de la población de origen haitiano y facilitar su integración.

\section{Bibliografía}

Alfonso, H. y Cedano, S. (2005). De problemas y oportunidades: intermediación urbana fronteriza en República Dominicana. Revista Mexicana de Sociología, 67(1), 99-126. Recuperado de https://www.jstor.org/ stable/3541556?seq=1\#page_scan_tab_contents

Alonso, J. A. y Gutiérrez, R. (coords.). (2010). Emigración y lengua. El papel del español en las migraciones internacionales. Madrid, España: Ariel.

Ariza, M. (2004). Obreras, sirvientas y prostitutas. Globalización, familia y 
mercado de trabajo en República Dominicana. Estudios Sociológicos, 22(1), 123-149. Recuperado de http://www.redalyc.org/articulo. oa? $\mathrm{id}=59806405$

Báez, F. y Lozano, W. (1985). Migración internacional y economía cafetalera. Estudio sobre la migración estacional de trabajadores haitianos a la cosecha cafetalera en República Dominicana. Santo Domingo, República Dominicana: Taina.

Bidegain, G. (2012). Los haitianos en el exterior: mitos y realidades. En G. Vega y C. Alba (coords.), Haití-México. Hacia una nueva política de cooperación (pp. 141-165). Ciudad de México: El Colegio de México, A.C.

Castor, S. (1971). La ocupación norteamericana de Haití y sus consecuencias (1915-1934). Ciudad de México: Siglo Veintiuno.

Castor, S. (1983). Migración y relaciones internacionales (el caso haitianodominicano). Ciudad de México: Universidad Nacional Autónoma de México.

Cayemittes, M., Fatuma, M., Bizimana, J., Barrére, B., Sévére, B., Cayemittes, V. y Charles, E. (2013). Enquête Mortalité, Morbidité et Utilisation des Services, Haïti, 2012. Calverton, MD: MSPP / IHE / ICF International. Recuperado de https://dhsprogram.com/pubs/pdf/FR273/FR273. pdf

Contreras, A. M. (2004). ¿Por qué los dominico-haitianos están colocados en la base de la estratificación socio-económica de los ciudadanos dominicanos? Mecanismos de exclusión socio-étnica en una sociedad mulata. Estudios Sociales, 37(138), 10-61.

Del Castillo, J. P. (1978). La inmigración de braceros azucareros en la República Dominicana, 1900-1930. Santo Domingo, República Dominicana: Universidad Autónoma de Santo Domingo (Cuadernos del CENDIA, 7).

Del Castillo, J. P. (2005). La formación de la industria azucarera dominicana entre 1872 y 1930. Discurso de ingreso como miembro de la Academia Dominicana de la Historia, 3 de enero.

Derby, R. y Turits, R. (1993). Historias de terror y los terrores de la historia: la masacre haitiana de 1937 en la República Dominicana. Estudios Sociales, 26(92), 65-76. Recuperado de https://es.scribd.com/docu ment/24231817/Turits-R-Derby-L-Historias-de-Terror-y-Los-Terroresde-la-Historia-La-Masacre-Haitiana-de-1937-en-la-Republica-Domi nicana

Duarte, I., Cuello, M., Santos, F., Wooding, B., Sangro, A., Aristy, J., ... Arboleda, J. (2011). Movimientos migratorios desde y hacia la Repúbli- 
ca Dominicana (Planificación y Desarrollo, II). Santo Domingo, República Dominicana: Secretaría de Economía.

Flacso / OIM (2004). Encuesta sobre los Inmigrantes Haitianos en República Dominicana. Santo Domingo, República Dominicana: Facultad Latinoamericana de Ciencias Sociales / Organización Internacional para las Migraciones.

Gaillard, R. (1981). Les blancs débarquent, 1916-1917. La république autoritaire. Puerto Príncipe, Haití: Le Natal.

Glick, J. y Van Hook, J. (2011). Does a house divided stand? Kinship and the continuity of shared living arrangements. Journal of Marriage and Family, 73(5), 1149-1164. Recuperado de https://www.ncbi.nlm.nih. gov/pmc/articles/PMC3258516/

Hintzen, A. (2016). A veil of legality. The contested history of anti-Haitian ideology under the Trujillo dictatorship. New West Indian Guide, 90(1/2), 28-54. Recuperado de https://brill.com/view/journals/nwig/90/1-2/articlep28_2.xml

Koolhas Gandós, M. (2015). Migración internacional de retorno en Uruguay: magnitud, selectividad y reinserción laboral en tiempos de crisis económica internacional (Tesis de maestría, Montevideo, Uruguay: Universidad de la República). Recuperado de https://www.colibri.udelar. edu.uy/jspui/bitstream/123456789/7697/1/TMDEP_KoolhaasMartin.pdf

Koolhaas, M. y Nathan, M. (2013). Inmigrantes internacionales y retornados en Uruguay. Informe de resultados del censo de población de 2011. Montevideo, Uruguay: INE / OIM / UNFPA.

Lozano, W. (1998). Jornaleros e inmigrantes. Santo Domingo, República Dominicana: Flacso / INTEC.

Lozano, W. (2005). La paradoja de las migraciones. El estado dominicano frente a la inmigración haitiana. Santo Domingo, República Dominicana: UNIBE / Flacso / SJRM.

Liversage, A. y Jakobsen, V. (2010). Sharing space-gendered patterns of extended household living among young Turkish marriage migrants in Denmark. Journal of Comparative Family Studies, 41(5), 693-715. Recuperado de https://www.jstor.org/stable/41604399?seq=1\#page scan_tab_contents

Menjívar, C. (2000). Fragmented ties: Salvadoran immigrant networks in America. Berkeley, CA: University of California Press.

Méroné, S. C. (2017). La integración de la población de origen haitiano en el mercado de trabajo de República Dominicana. Un análisis sociodemográfico (Tesis de doctorado en Estudios de Población, El Colegio de México, A.C., Ciudad de México). 
Michel, W. (2010). Toute la vérité sur le massacre du cochon créole. Le Nouvelliste, 27 de septiembre.

Miranda, S. (2014). Citizens without a nation: The construction of Haitian illegality and deportability in the Dominican Republic (Tesis de maestria en Sociologia, Illinois State University). Recuperado de https://ir.library. illinoisstate.edu/cgi/viewcontent.cgi?article $=1146 \&$ context $=$ etd

Moral, P. (1978). Le paysan Haïtien (Étude sur la vie rurale en Haïti). Puerto Príncipe, Haití: Fardin (Collection du Bicentenaire d'Haïti 1804-2004).

Moya Pons, F. (1986). El batey. Estudio socioeconómico de los bateyes del Consejo Estatal del Azúcar. Santo Domingo, República Dominicana: Fondo para el Avance de las Ciencias Sociales.

Moya Pons, F. (1992). Las tres fronteras: introducción a la frontera dominicohaitiana. En W. Lozano (coord.), La cuestión haitiana en Santo Domingo. Migración internacional, desarrollo y relaciones inter-estatales entre Haití y República Dominicana. Santo Domingo, República Dominicana: Facultad Latinoamericana de Ciencias Sociales.

Oficina Nacional de Estadística (ONE). (2009). Encuesta Nacional de Hogares de Propósitos Múltiples (Enhogar-2007). Informe general. Santo Domingo, República Dominicana: Oficina Nacional de Estadística.

Oficina Nacional de Estadística (ONE). (2010). IX Censo Nacional de Población y Vivienda 2010. Santo Domingo, República Dominicana: Oficina Nacional de Estadística. Recuperado de http://censo2010.one.gob.do/ index.php? module $=$ articles $\&$ func $=$ display $\&$ aid $=213$

Oficina Nacional de Estadística (ONE). (2012). Encuesta Nacional de Inmigrantes, 2012. Santo Domingo, República Dominicana: Oficina Nacional de Estadística. Recuperado de https://www.one.gob.do/encuestas/ eni

Pascual, V. y Figueroa, D. (2005). La porosa frontera y la mano de obra haitiana en la República Dominicana. Caribbean Studies, 33(1), 251-280. Recuperado de https://www.jstor.org/stable/25613467?seq=1\#page_ scan_tab_contents

Peguero, V. (2004). The militarization of culture in the Dominican Republic, from the captains general to general Trujillo. University of Nebraska Press.

Peña, A. (2015). Admite uso masivo de haitianos en el agro viola el Código de Trabajo. Acento, 8 de marzo (artículo de prensa). Recuperado de http://acento.com.do/2015/economia/8228982-admite-uso-masivo-dehaitianos-en-el-agro-viola-el-codigo-de-trabajo

Perdomo, N. (2016). Análisis crítico de la sentencia TC/0168/13. Memorias. Revista Digital de Historia y Arqueología desde el Caribe, 12(28), 93- 
135. Recuperado en http://rcientificas.uninorte.edu.co/index.php/memo rias/article/view/8177/8212

Pierre, J. (2013). Les étudiants haïtiens en République Dominicaine et la reconstruction d'Haïti. Haïti Perspectives, 2(3), 69-73. Recuperado de https://drive.google.com/file/d/0B1mKTpp0zLqmN19TYTZ5R2JKaG8/ edit

Price-Mars, J. (1953). La République D'Haïti et la République Dominicaine. Les aspects divers d'un problème d'histoire de géographie et d'ethnologie (Collection du Bicentenaire d'Haïti 1804-2004, tomo II). Puerto Príncipe, Haití: Fardin.

Riveros, N. (2014). Estado de la cuestión de la población de los bateyes dominicanos en relación a la documentación. Santo Domingo, República Dominicana: Búho.

Santamaría García, A. (1995). La industria azucarera y la economía cubana durante los años veinte y treinta. La crisis del sector exportador, comercial y azucarero y su incidencia en la sociedad y en la economía insular (Tesis doctoral, Madrid, España: Universidad Complutense). Recuperado de https://eprints.ucm.es/2441/1/T20430.pdf

Silié, R., Segura, C. y Dore, C. (2002). La nueva inmigración haitiana. Santo Domingo, República Dominicana: Facultad Latinoamericana de Ciencias Sociales.

Tejada, Y. (2001). Bateyes del Estado. Encuesta Socioeconómica y de Salud de la Población Materno-Infantil de los Bateyes Agrícolas del CEA, diciembre 1999. Santo Domingo, República Dominicana: USAID.

Turits, R. (2002). A world destroyed, a nation imposed: The 1937 Haitian massacre in the Dominican Republic. Hispanic American Historical Review, 82(3), 589-635. Recuperado de https://read.dukeupress.edu/ hahr/article/82/3/589/34983

Vargas, T. (2010). Procesos de integración y construcción de la identidad de la población dominicana de ascendencia haitiana de segunda y tercera generación. Santo Domingo, República Dominicana: Servicio Jesuita a Refugiados y Migrantes.

Vega, B. (1988). Trujillo y Haití. Santo Domingo, República Dominicana: Fundación Cultural Dominicana.

Victoriano-Martínez, R. A. (2010). Rayano: una nueva metáfora para explicar la dominicanidad (Tesis doctoral, University of Toronto, Canadá). Recuperado de https://tspace.library.utoronto.ca/bitstream/1807/26334/1/ Victoriano-Mart\%C3\%ADnez_Ram\%C3\%B3n_A_201011_PhD_thesis. pdf

Wooding, B. y Moseley-Williams, R. (2004). Inmigrantes haitianos y do- 
minicanos de ascendencia haitiana en la República Dominicana. Santo Domingo, República Dominicana: Cooperación Internacional para el Desarrollo / Servicio Jesuita a Refugiados y Migrantes.

Wright, B., Caspi, A., Moffitt, T. y Silva, P. (1998). Factors associated with doubled-up housing: A common precursor to homelessness. Social Service Review, 72(1), 92-111. Recuperado de https://www.jstor.org/ stable/10.1086/515747?seq=1\#page_scan_tab_contents

\section{Acerca del autor}

Schwarz Coulange Méroné es doctor en Estudios de Población por El Colegio de México, A.C. y maestro en Población y Desarrollo por el Centro de Estudios en Población y Desarrollo (Centre d'Études en Population et Développement) de la Universidad Estatal de Haití (Université d'Etat d'Haïti). Se dedica principalmente a la investigación académica. Sus principales temas de investigación son: migración haitiana en América latina, migración desde y hacia México, integración laboral y social de poblaciones de origen extranjero en sus países de acogida, segregación laboral y espacial. Actualmente coordina un proyecto de investigación en El Colegio de México, A.C. sobre la población haitiana en México.

Recepción: 2 de agosto de 2017.

Aceptación: 8 de abril de 2018. 